\title{
A SEXUALIDADE ENTRE A PSICANÁLISE FREUDIANA E A FENOMENOLOGIA DE MAURICE MERLEAU-PONTY
}

\author{
Diego Luiz Warmling ${ }^{1}$
}

\begin{abstract}
RESUMO
Buscaremos explorar neste artigo a relação entre sexualidade e existência que a fenomenologia de Maurice Merleau-Ponty desenvolve quando reinterpreta os estudos sobre a sexualidade humana encontrados na teoria freudiana. Sob a batuta de Três Ensaios Sobre a Teoria da Sexualidade, num primeiro momento, contextualizaremos o modo como a sexualidade é compreendida com base numa teoria das pulsões, numa caracterização da sexualidade infantil e numa teoria da libido. Todavia, veremos também como há algo de censurável na escopo freudiano, pois quando reflete sobre sua pratica, o analista serve-se de uma teoria formulada em terceira pessoa e se distancia do discurso produzido pelo consulente (em primeira pessoa). A sexualidade seria antes uma força biológica que, distante, regeria as ações humanas. Assim, se desejamos devolver a vida mental ao mundo da vida sem abdicarmos do aspecto essencialmente sexual de nossos desejos e paixões, será em Merleau-Ponty onde estes atos não serão mais objetos distantes, e sim vivências que, corporificadas, expressam a maneira pela qual co-pertencemos a um mundo interhumano. Isto posto, traçaremos um panorama acerca dos modos como Merleau-Ponty concebe a noção de corpo. Ora, sendo potência exploratória e veículo do ser-no-mundo, este só pode ser compreendido tendo em vista outras realidades sensíveis, o que nos faz considerar a sexualidade como o modo de ser que evidencia nossa co-determinação com as coisas. Partindo da estrutura psicanalítica, Merleau-Ponty revelará a sexualidade como uma atmosfera que não é nem transcendência da vida humana, nem imagem de representações conscientes ou inconscientes, mas coextensiva à vida. Sendo assim, veremos que grande parte dos problemas da psicanalise não são necessariamente de ordem sexual, mas estão ligados à atitude geral de ser no mundo, que envolve o horizonte sexual.
\end{abstract}

Palavras chave: Fenomenologia. Psicanálise. Sexualidade.

\footnotetext{
${ }^{1}$ Área de Formação: Filosofia; Titulação: Mestrando; Instituição de Origem: Programa da Pós-Graduação em Filosofia da UFSC; Fomento: CAPES CNPQ; E-mail Profissional: diegowarmling @ hotmail.com
} 


\begin{abstract}
We will explore in this article the relationship between sexuality and existence that Maurice Merleau-Ponty's phenomenology develops when he reinterprets the studies on human sexuality found in Freudian theory. Based on Three Essays on Sexuality Theory, we will first contextualize how sexuality is understood based on a theory of drives, a characterization of infantile sexuality, and a theory of libido. However, we will also see how there is something objectionable in Freud, because when he reflects on his practice, the analyst uses a theory formulated in the third person and distances himself from the discourse produced by the patient (in the first person). Sexuality would be a biological force that, far away, would govern human actions. If we wish to return mental life to the world of life without giving up the essentially sexual aspect of our desires and passions, it will be in Merleau-Ponty that these acts will not be distant objects, but experiences expressing the way in which we belong to a world Inter-human interaction. We will give an overview of the ways in which Merleau-Ponty conceives the notion of body. Being an exploratory power and vehicle of the being-in-the-world, it can only be understood in view of other sensitive realities, which makes us consider sexuality as the mode of being that shows our co-determination with things. Starting from the psychoanalytic structure, Merleau-Ponty will reveal sexuality as an atmosphere that is not transcendence of human life, is not an image of conscious or unconscious representations, but coextensive with life. We will see that much of the problems of psychoanalysis are not necessarily sexual, but they are linked to the general attitude of being in the world, which involves the sexual horizon.
\end{abstract}

Key words: Phenomenology. Psychoanalysis. Sexuality. 


\section{INTRODUÇÃO}

Dos estudos que Merleau-Ponty dedica à corporeidade, este artigo versa sobre o modo como sexualidade e existência são compreendidas à luz da reinterpretação fenomenológica da psicanálise freudiana. De Freud, veremos como nossos atos não são determinados apenas por um inconsciente involuntário, mas possuem uma significação pulsional de ordem sexual, latente desde a infância e que teria de ser libidinalmente direcionada se quiséssemos manter o seu controle frente ao social. Contudo, veremos que, quando reflete sobre sua prática, o analista serve-se de uma formulação em terceira pessoa e se distancia do discurso produzido pelo consulente (em primeira pessoa), permitindo-nos assim dizer que na psicanálise a sexualidade é uma determinante extrínseca da conduta humana.

Se desejamos devolver a vida mental ao mundo da vida sem abdicar do aspecto sexual de nossos desejos, é em Merleau-Ponty onde a sexualidade não será mais um objeto distante, mas vivência que, corporificada, expressa nosso co-pertencimento à alteridade. Nem objetivista, nem subjetivista, o corpo é aqui nossa forma ampla de inserção no mundo da vida: é veículo do ser-no-mundo. E se é por ele que o ser vai ao mundo, só será compreendido tendo em vista suas relações com a alteridade. Sem apresentar-se independente da infraestrutura existencial humana, a sexualidade será, assim, a evidencia de nossa relação mundana com o outro.

Partindo da teoria freudiana, Merleau-Ponty nos revelará um horizonte que não é nem transcendência da vida humana, nem imagem de representações conscientes ou inconscientes, mas coextensivo à vida. Veremos como parte dos problemas psicanalíticos não remetem necessariamente à estrutura sexual, mas estão ligados à atitude geral de ser no mundo, que é sexuado. Esta leitura devolve o ser à sua vivência de mundo e dissolve a ideia de uma identidade objetiva, pois, sendo em relação com a alteridade, o eu será sempre implícito e misterioso.

\section{Freud e a sexualidade humana.}

Sigmund Freud, ao analisar os sintomas da neurose em conjunto com a experiência clínica, encontra, por detrás destes, aspectos emocionais que tem a ver com excitações de natureza sexual e conflitiva. A importância concedida à esta questão não apenas foi motivo 
de rompimento com alguns dos estudiosos de sua época, como o levou a escrever duas de suas principais obras: A Interpretação do Sonhos (1900) - donde os discursos sobre o inconsciente, assim como o desejo - e Três Ensaios sobre a Teoria da Sexualidade (1905) - onde instaura o conceito de pulsão para tratar especificamente da sexualidade humana. Isto posto, se nas diversas espécies animais a função sexual manifesta-se segundo padrões biológico pré-fixados geneticamente, a partir da obra de 1905, veremos como, para além de relações instintuais, a sexualidade humana emerge "sob uma aparência errática e súbdita a uma lógica diferente daquela que rege os instintos animais" (JORGE, 2008, p. 21).

Empenhado em restituir o sentido de certas condutas até então vistas como desprezíveis e sem importância, para Freud os atos humanos não são determinados somente por um inconsciente que nos escapa, mas possuem um sentido falho e involuntário que os determina. Para o psicanalista, no mais das vezes transmitimos mensagens que, em verdade, buscam expressar algo totalmente diferente do que se mostra à primeira vista. A recorrência "de um ato involuntário reside no fato de ele ser o substituto de um ato ideal, de uma ação impossível que, em termos absolutos, deveria ter-se produzido, mas não ocorreu" (NÁSIO, 1995, p. 31). Diferentemente dos atos ideativos - que fazem referência deliberada a um fato vivido, seja ele passado ou futuro -, os atos involuntários possuem sentido na medida em que são a substituição de um ideal não realizado. Deste modo, dado que as produções do inconsciente do outro influem sobre as fontes do inconsciente subjetivo (e vice-versa), o teor oculto destes nossos atos será, portanto, a grande descoberta da psicanalise freudiana, a saber: que os mesmos possuem sempre uma significação pulsional de ordem sexual. Nossa conduta é a todo instante sexual porque fonte e alvo são sexuais, sendo fonte um processo excitatório correspondente num órgão e alvo, a supressão da tensão ocasionada pela excitação, cuja forma perfeita seria o incesto: “A fonte da pulsão é um processo excitatório num órgão, e seu alvo imediato consiste na supressão desse estímulo orgânico" (FREUD, 1989, p. 159)

Isto posto, vemos como Freud se depara com a inegável perversidade sexual de seus pacientes. E é tomando como ponto de partida os discursos já postulados que sustenta não ser mais possível assentar a sexualidade humana sob o prisma do instinto (instinkt); esta deveria ser compreendida através do conceito de pulsão (Trieb). Ora, predominantemente assentadas numa noção finalista onde a atividade sexual seria entendida como herança de espécie animal que, pouco variante entre os indivíduos, pressuporia uma sequência temporal raramente suscetível à alterações, se até o momento 
grande parte das teorias amparavam-se nesta de instinto para compreender o erotismo humano, Freud, por sua conta, não mais partirá desta concepção. O diferencial de Três Ensaios Sobre a Teria da Sexualidade reside, afinal, no fato de se dispor a compreensão da sexualidade humana a partir de ideia de pulsão, que atuará num campo ainda mais amplo do que a atividade instintual, cujas implicações estão nitidamente definidas.

Diferentemente dos instintos, dizemos, com efeito, que a pulsão trata-se de um processo dinâmico de pressão e descargas energéticas voltadas para fins específicos. Tal conceito corresponde à um conjunto de forças (cargas energéticas) que, da interação com o meio, crescem no organismo humano e que, tal qual uma panela de pressão, impulsionam o corpo para um alvo determinado. Sendo desde sempre desviante à conduta animal, uma pulsão surge "numa excitação corporal (estado de tensão); o seu alvo é suprimir o estado de tensão que reina na fonte pulsional; é no objeto ou graças a ele que a pulsão pode atingir o seu alvo" (LAPLANCHE \& PONTALIS, 1986, p. 506). Levando em conta a privação de substâncias necessárias à vida ou a presença de estímulos negativos, este conceito é enfim utilizado para entender a relação entre psique e soma - donde deriva a noção de libido.

Da diferenciação entre objeto sexual - ou seja, a "pessoa de quem provém a atração sexual” (FREUD, 1989, p. 127) - e objetivo (alvo) sexual - a saber: "a ação para a qual a pulsão impele" (FREUD, 1989, p. 127) -, a noção de pulsão sexual nasceria, então, de uma zona erógena do corpo que, tendo em vista um ideal fantástico, expressar-se-ia por meio de atos substitutivos, por sua vez compreendidos como atos forjados em fantasias e dispostos conforme a imagem de um objeto fantasiado. Diferentemente das teorias cujos padrões de conduta estão fixados pelo instinto, do ponto de vista psicanalítico, uma pulsão sexual não apenas independeria do objeto sexual, como seria antes um desvio, pois, compreendida ao longo da história do próprio indivíduo, seria o lugar de tantas observações que se tornaria quase impossível de se determinar, por exemplo, o grau de perversão permitido para cada pessoa: "a extraordinária difusão das perversões força-nos a supor que tampouco a predisposição às perversões é uma particularidade rara, mas deve, antes, fazer parte da constituição que passa por normal” (FREUD, 1989, p. 160). De natureza conflitiva ${ }^{2}$, sexual será, portanto, toda conduta que, de uma zona erógena do corpo (boca, ânus, olhos, voz, pele, etc.), apoia-se numa fantasia (realizável ou não) e possibilita certa forma de prazer. E se é deste modo, há de se considerar também a constituição que conteria o germe de todas

\footnotetext{
${ }^{2}$ Ao longo de toda a obra, Freud sustenta que a pulsão sexual exerce uma ação de recalcamento: "é o objeto privilegiado do recalcamento no inconsciente" (LAPLANCHE \& PONTALIS, 1986, p. 519)
} 
as perversões: uma vida sexual infantil.

Com efeito, do que entende por ser um grave erro teórico acerca do desenvolvimento da sexualidade ${ }^{3}$, será no segundo dos Três Ensaios sobre a Teoria da Sexualidade onde o alemão desenvolverá este estudo fundamental à teoria psicanalítica. Mostra-se à esta altura não apenas as características essenciais da pulsão sexual revelando sua evolução -, mas que esta se compõe de diversas fontes possíveis. Polimorfa, perversa e autoerótica (pulsão sexual + excitação erógena = satisfação sem a recorrência de um objeto externo), a caracterização de uma sexualidade infantil vem alargar o que até então se entendia por vida sexual, pois não apenas nos faz indagar a existência de excitações precoces, como nos leva a reconhecer certas atividades muito próximas às perversões adultas. Na medida em que 1) não estão somente atreladas à funções biológicas (nutrição, por exemplo) e 2) buscam satisfação por um objeto (ideal ou não) de prazer, a infância é repleta de impulsos que possuem sempre a potência de se tornarem fonte de excitação sexual. Assim, se desde o início admitirmos que as pulsões infantis envolvem outras pessoas como objetos sexuais, vale ressaltar, pela admissão de sexualidade infantil, que 1) para cada indivíduo um erotismo se faz atual, 2) que os complexos anímicos de cada pessoa não implicam patologia ${ }^{4}$ e 3 ) que a sexualidade não diz respeito apenas à atividade genital, mas corresponde toda uma série de excitações ou atividades presentes desde a tenra idade.

No entanto, mesmo que possamos evidenciar, na criança, sensações prazerosas em zonas erógenas do corpo, durante este período, excitação e satisfação ainda não estão nitidamente diferenciadas. Por serem essencialmente pré-genitais e anárquicas, para Freud estes impulsos ainda são bastante indiferenciados, o que nos levaria a esquecê-los com o decorrer do tempo (amnésia infantil). Assim, é somente com o avanço do desenvolvimento sexual que cada situação assumirá seu papel e lugar no corpo. Somente no devido tempo ocorre a organização da energia pulsional nas zonas erógenas específicas, assim como suas respectivas etapas: fases oral, anal-sádica e fálica. É, portanto, com início da vida adulta que "os genitais começam e funcionar como aparelho especial de descarga" (FENICHEL, 1981, p. 56). Isto posto, passemos então à puberdade e à teoria da libido.

Se durante a infância a sexualidade é essencialmente difusa e autoerótica, na

\footnotetext{
${ }^{3}$ Estamos nos referindo ao postulado segundo o qual a pulsões sexuais só despertariam no período da puberdade, estando ausentes durante infância.

${ }^{4}$ Segundo Freud, a diferença entre normal e anormal reside "na intensidade relativa de cada componente da pulsão sexual e no uso que lhes é dado no decorrer do desenvolvimento" (FREUD, 1989, p. 193)
} 
puberdade, encontrará o objeto sexual sob o primado da zona genital: "a pulsão sexual coloca-se a serviço da função reprodutora; torna-se altruísta, por assim dizer" (FREUD, 1989, p. 195). Tal altruísmo deve ser entendido como um ultrapassamento da satisfação individual autoerótica em prol da manutenção da espécie. Ora, se de um lado ocorre o desenvolvimento dos órgãos responsáveis pela descarga dos estímulos sexuais genitais, do outro, estes órgãos só se movimentam levando em conta o mundo exterior, o organismo interior e a própria vida mental. Desta feita, é buscando um diálogo entre as perspectivas biologicistas e psicológicas que, com base na caracterização da vida sexual pubescente, Freud defenderá: no limiar entre mental e soma, produz-se uma excitação de ordem sexual. Em prol de uma descarga energética, o estimulo apropriado de uma zona erógena, apesar de agora subordinado à função reprodutora, provoca um aumento do estado de tensão que, uma vez satisfeito, faz escoar a energia pulsional, descodeando assim certo estado de prazer $^{5}$. Esta energia é descrita por Freud como sendo a libido; vejamos.

Da necessidade de mantermos, frente a ordem social, o controle sobre a nossa vida sexual, o conceito de libido vem designar não somente o que, do latim, significa "vontade" ou "desejo", mas estaria sobretudo relacionado ao "substrato das transformações da pulsão sexual quanto ao objeto (deslocamento dos investimentos), quanto ao alvo (sublimação, por exemplo) e quanto a fonte de excitação sexual (diversidade das zonas erógenas)" (LAPLANCHE \& PONTALIS, 1986, p. 343). Essencialmente de natureza sexual, ainda que seja difícil assumir uma definição unívoca em todo o conjunto a obra freudiana, podemos dizer que no escopo de Três Ensaios Sobre a Teoria da Sexualidade tal conceito é compreendido como uma força apta a mensurar as transformações/processos qualitativa e quantitativamente variáveis no domínio das excitações sexuais. Ora, se por um lado Freud defende certo aspecto qualitativo segundo o qual, diferentemente de $\mathrm{Jung}^{6}$, a libido nunca cobriria todo o campo pulsional, por outro, ao firmar-se como conceito quantitativo, aparece tal qual uma variável que, de acordo com sua produção, aumento ou diminuição, distribuição e deslocamento, nos possibilitariam explicar os fenômenos psicossexuais. Para Freud, a libido jamais poderia ser equacionada como se fosse uma energia mental inespecífica e indiferenciada desde sua origem. Por mais que em sua totalidade possa vir a

\footnotetext{
${ }^{5}$ Para Freud, a excitação sexual possui dois indicadores: as mentais, que "consistem num estado de tensão" e as corporais, que indicam "alterações [...] nos órgão genitais" (GARCIA-ROZA, 2014, p. 108). Sendo que excitação deve ser compreendida como um aumento da tensão (muitas vezes relacionada com o desprazer), o prazer - divido em duas fazes ("pré-prazer" e "prazer final") - será a redução desta tensão.

${ }^{6}$ Segundo Freud, em Jung o conceito de libido estaria sobretudo relacionado a uma "força pulsional psíquica em geral" (FREUD, 1989, p. 206), podendo ou não ser sexualizada.
} 
ser dessexualidada, em instância alguma poderá assumir a primazia de todos os significantes pulsionais, sendo sempre tácita aos processos anímicos em geral. De acordo com o desenvolvimento desta análise, quando separamos a libido das demais modalidades de energia psíquica, "damos expressão à premissa de que os processos sexuais do organismo diferenciam-se dos processos de nutrição por uma química especial" (FREUD, 1989, p. 205). Desta forma, se por um lado ela é secundária aos processos sexuais, quantitativamente falando, fornece os meios para nos permitir mensurar a produção, o aumento, a diminuição, o deslocamento, etc. de todos os processos de excitação sexual, incluindo nisto os afetos e o amor.

Retirada da teoria da efetividade, enquanto a pulsão situa-se - tal qual uma força de pressão - no limiar entre os âmbitos psíquico e somático, a libido, por sua vez, vem expressar o dinamismo energético da vida psíquica da pulsão sexual. Mantendo-se próxima do desejo sexual, na medida em que este se dá nos limites do psicossomático, libido seria, por assim dizer, a manifestação da vida psíquica destas pulsões: "na medida em que a pulsão sexual representa uma força que exerce uma 'pressão', a libido é definida [...] como a energia dessa pulsão" (LAPLANCHE \& PONTALIS, 1986, p. 344). Presente da infância à vida adulta, de natureza essencialmente sexual e irredutível às outras formas de energia pulsional, não só seria predominantemente masculina (ativa) ${ }^{7}$, como, no que diz respeito aos distúrbios neuróticos e psicóticos, deveria "expressar todos os fenômenos observados e os processos deduzidos em termos de economia libidinal” (FREUD, 1989, p. 205). Uma insuficiência sua pode muito bem resultar num acumulo de tensão, por sua vez exteriorizado através de fixações comportamentais não téticas pertinentes ao plano sintomático - na medida em que um sintoma mobiliza certa quantidade extra de energia em detrimento do empobrecimento do nível de outras atividades quaisquer.

Desta forma, posto que a energia da pulsão sexual é a libido e o seu objetivo é a satisfação, surgiriam problemas quando o desenvolvimento da libido, incapaz de ir adiante, fixava-se em algum dos estágios pré-genitais e, fora da consciência, produzia efeitos involuntários sobre o comportamento. E se desejássemos manter a ordem social, a força da libido deveria ser direcionada de tal modo que, desde a infância, nossos impulsos precisariam de orientação externa. De uma teoria elaborada em "terceira pessoa", caberia, portanto, à terapia psicanalítica não só fazer com que o paciente trouxesse à consciência

\footnotetext{
${ }^{7}$ No escopo da psicanálise, masculino e feminino devem ser entendidos enquanto atividade e passividade, sendo que o ser humano é essencialmente bissexual e a libido independe de qualquer sexo.
} 
este material reprimido mas torná-lo capaz de, objetivamente, resolver seus problemas, sabendo sempre o que haveria por detrás deles: "a psicanalise não cura apenas tornando inteligível ao sujeito sua própria vida [...] trata-se de fazê-lo reviver e liquidar, a favor da relação com o psicanalista, seus antigos conflitos” (MERLEAU-PONTY, 1990a, p. 87).

No entanto, contaminada pelos pressupostos de sua época, há, aí, algo de censurável, pois o paciente não poderia por-se a refletir senão a partir de uma tese objetivista de sí (distante daquele discurso formulado, sobretudo, em primeira pessoa). E a sexualidade seria, por assim dizer, uma força extrínseca que de algum modo orientaria as ações humanas. Desta feita, se desejamos devolver a vida mental ao mundo da vida, precisamos, recolocar seu o arcabouço conceitual freudiano. Será através da obra Maurice Merleau-Ponty que, sem abdicar do aspecto essencialmente sexual, veremos como nossos desejos e paixões não são mais objetos longínquos e externos à nossa conduta. A partir do escopo de sua fenomenologia, a sexualidade será antes uma vivência que, em carne e osso, expressa a maneira pela qual co-pertencemos a um mundo inter-humano. Vejamos.

\section{Merleau-Ponty e o Horizonte sexual: uma reinterpretação fenomenológica da psicanálise.}

Ao vislumbrar os modos como o ser interage com as coisas no mundo ${ }^{8}$, é por meio da percepção e da consciência encarnada que Maurice Merleau-Ponty compreende o homem. Para o francês, este jamais poderia lidar com as coisas ao seu redor sem antes partir de certos pressupostos que, se comparados àquela tradicional antinomia sujeitoobjeto - encontrada, por exemplo, na tradição cartesiana -, remeteriam a uma espécie de envolvimento pré-reflexivo ou irrefletido que, em primeira pessoa, o ser mantem com as coisas: como uma presença inalienável, "se para mim um projeto e uma interpretação do real são possíveis, é porque estou irremediavelmente ligado com o real num sentido radical" (WAELHENS, 2006, p. XII). Aqui entendida como um trazer à tona certas experiências fundamentais de um mundo que, nem puramente empirista nem totalmente intelectualista, mescla ora sujeito ora objeto, ora existência ora essência, e cuja meta está em restituir o contato ingênuo com as coisas, é somente por uma conexão intima entre vida

\footnotetext{
${ }^{8} \mathrm{Na}$ Fenomenologia da Percepção, o autor define mundo como um natural que se apresenta para além de sua existência para mim. É algo em si que não precisa ser percebido para existir.
} 
perceptiva, corpo e ser-no-mundo que o homem poderia projetar-se entre as coisas e, assim, revelar o verdadeiro "sentido do ser": "o corpo é o veículo do ser no mundo, e ter um corpo é, para um ser vivo, juntar-se a um meio definido, confundir-se com certos projetos e empenhar-se continuamente neles" (MERLEAU-PONTY, 2011, p. 11).

Diferentemente de certos pressupostos segundo os quais a mente seria, por exemplo, um "recipiente" de pensamentos, desejos e vontades acessíveis somente pela introspecção, para Merleau-Ponty, ser corpo é, antes, estar amarrado a certo mundo, pois é no espaço, e sua espacialidade "é o desdobramento de seu ser corpo, a maneira pela qual ele se realiza como corpo" ou síntese corporal (MERLEAU-PONTY, 2011, p. 206). Nem puro objeto nem pura ideia, sensível entre outros sensíveis, "não é da ordem do 'eu penso', mas do 'eu posso"' (CHAUI, 2002, p. 68) - é potência exploratória. Segundo Dupond, é "a própria existência em seu movimento de transcendência: é a potência de se juntar às coisas e se sincronizar com elas" (DUPOND, 2010, p. 13). Para além de uma exterioridade mecanicista ou determinista ${ }^{9}$, na junção entre natureza e liberdade, o corpo (corpo próprio) é a biface pela qual as coisas se ordenam para mim. Sempre envolvido "em nossas tomadas de posições subjetivas" (FERRAZ, 2006, p.100), constitui não só a estrutura estável de nossa existência, como é veículo do ser no mundo, sendo que, se de minha subjetividade vejo transparecer outra subjetividade investida de direitos iguais, esta não apenas esboça meu campo perceptivo, como revela 1) uma verdadeira comunicação e 2) a dimensão do ser intersubjetivo ou da objetividade.

Deste modo, preocupado em fundamentar a noção de comportamento como uma totalidade aberta (natureza + organismo + psiquismo), o corpo será num só tempo $a$ ) principio motor (esquema corporal) ${ }^{10}, b$ ) ser sexuado e $c$ ) lugar da expressão ${ }^{11}$. E uma vez que "nossa meta constante é pôr em evidência a função primordial pela qual fazemos existir para nós, pela qual assumimos o espaço, o objeto ou o instrumento e descrever o

\footnotetext{
${ }^{9}$ Na Fenomenologia da Percepção, Merleau-Ponty entende a noção de corpo segundo duas acepções: corpo objetivo e corpo próprio (corpo fenomenal). Levando em conta a própria estruturação deste projeto, não trataremos aqui (em nota) desta segunda acepção, pois acreditamos já estar compreendida em toda a proposta. Sendo assim, partindo da fisiologia e da psicologia clássicas, no que tange à primeira acepção (corpo objetivo), diferentemente da segunda (para a qual o corpo possui intenções próprias que o levam a agir como totalidade portadora de todas as correlações possíveis), nesta opera certo objetivismo no qual o corpo é compreendido como "o modo de ser de um 'coisa"" e está diretamente conectado a uma espécie de gênese virtual constituinte onde, partes extra partes, só se admitem relações mecânicas causais entre sí e os objetos externos: é "um microfenômeno" (MERLEAU-PONTY, 2000, p. 348) que, na tentativa de objetividade, propõe-se "decompor a excitação e a reação em uma multiplicidade de processos parciais, exteriores uns aos outros tanto no tempo quanto no espaço" (MERLEAU-PONTY, 2006, p. 7).

${ }^{10}$ Pois "o contorno de meu corpo é uma fronteira que as relações espaço ordinárias não transpõem" (MERLAU-PONTY, 2011, p. 143)

${ }^{11}$ Pois "a fala exprime nosso modo de ser no mundo intersubjetivo" (CHAUI, 2002, p. 69)
} 
corpo enquanto lugar desta apropriação" (MERLAU-PONTY, 2011, p. 213), se buscamos devolver o homem à sua vivência de mundo e revelar a gênese do ser, será a partir da sexualidade que, para além de certo objetivismo científico, Merleau-Ponty revelará às teorias clássicas - incluindo Freud - seus próprios limites. Vejamos.

Para o francês, nossa relação com o mundo está incluída na relação do corpo consigo mesmo. No entanto, ao pensar o esquema corporal, este só faz sentido se compreendido em relação com outros esquemas corporais. Para além de uma experiência para mim, se faz necessário considerar certa atmosfera que evidencie nossa relação com o mundo sem, contudo, apresentar-se independente da infraestrutura existencial humana: nossa atmosfera sexual e afetiva. Será preciso considerá-la como parte constituinte do nosso trato com o mundo que, de nossas experiências, só tem sentido e realidade para nós. Assim, disposto a reinterpretar a psicanalise freudiana à luz de pressupostos fenomenológicos, devemos, a partir de Merleau-Ponty, procurar ver como os seres e coisas se põem para nós pelo desejo ou pelo amor para só então compreendermos como as coisas podem em geral ser ou existir.

Com efeito, nossa ligação com a alteridade não é uma relação de conhecimento objetivo (causa e efeito), se constitui, antes, "através do nosso ser total, em que o caráter afetivo se faz presente desde o início" (FURLAN, 1998, p.242): trata-se de considerar a sexualidade tanto como um mosaico de sensações que não se compreendem e só se explicam por um esquematismo corporal, quanto de dizer que, atravessadas por um intelecto, simples representações podem deslocar nossos estímulos e constituir valores que a princípio não tem relação aparente com nossos prazeres e dores naturais. Entre o automatismo (empirismo) e a pura representação (intelectualismo), as coisas são, portanto, apreendidas na mesma medida que o horizonte dos nossos desejos e emoções nos permitem. Sendo assim, da relação que estabelecemos com os outros por nossa abertura afetiva, as análises de Merleau-Ponty em O Corpo como Ser Sexuado nos levam a admitir uma zona vital onde se compõem as possibilidades sexuais de cada pessoa.

Imanente à vida sexual, é preciso que se considere na própria existência também uma função primordial que garanta seu desdobramento: uma EROS ou LIBIDO capazes de animar um mundo original, dar significação sexual aos estímulos exteriores e esboçar o uso que cada sujeito fará de seu corpo, sendo que este não deverá ser mais entendido como um objeto qualquer, mas como estrutura subtendida num esquema sexual deveras particular. Partindo tanto do caso Schneider (Cf. MERLEAU-PONTY, 2011, pp. 216-221), quanto do 
caso da Jovem Afônica (Cf. MERLEAU-PONTY, 2011, pp. 221-226), Merleau-Ponty não só nos revela, pela sexualidade, modos de ser diferentes da daquela "normalidade" objetivista, como nos faz entender que a percepção erótica não é uma cogitação (cogitatio) que visa um cogitado (cogitatum); ela se faz no mundo, não numa consciência laborativa. Há em cada sujeito uma compreensão que não passa pelo entendimento - que "não é a pura 'consciência de alguma coisa"' (GILES, 1979, p. 256) - mas que, enquanto projeto em direção ao outro, "compreende cegamente, ligando um corpo a um corpo" (MERLEAUPONTY, 2011, p. 217). Afastando-se tanto de um empirismo ${ }^{12}$, quanto de um intelectualismo $^{13}$, "trata-se não de um automatismo periférico, mas de uma intencionalidade que segue o movimento geral da existência e que se abranda com ele" (GILES, 1979, p. 257).

É neste ponto onde podemos encontrar as principais observações de Merleau-Ponty em relação à questão da sexualidade na psicanálise:

"quaisquer que tenham sido as declarações de [...] Freud, as investigações psicanalíticas resultam de fato não em explicar o homem pela infraestrutura sexual, mas em reencontrar na sexualidade as relações e as atitudes que anteriormente passavam por relações e atitudes de consciência, e a significação da psicanálise não é tanto a de tornar biológica a psicologia quanto a de descobrir um movimento dialético em funções que se acreditavam 'puramente corporais', e reintegrar a sexualidade no ser humano."(MERLEAU-PONTY, 2011, p. 218)

Segundo Merleau-Ponty, ainda em Freud seria um equívoco dizer que o método psicanalista se opõe ao método fenomenológico, pois, sem dar-se conta, aquele (Freud) contribui à fenomenologia quando afirma "que todo ato humano 'tem um sentido', e ao procurar em todas as partes compreender o acontecimento, em lugar de relacioná-lo às condições mecânicas” (MERLEAU-PONTY, 2011, pp. 218-219). No entanto, diferentemente da psicanálise, aqui a sexualidade não deve ser uma realidade autônoma pois, reciproca às demais esferas da vida, está antes ligada a todo ser cognoscente e atuante. Com efeito, se em Freud a libido era restrita à atividade sexual, em Merleau-Ponty este conceito, ainda que possua uma conexão intima com nossas atividades genitais, não se limitará ao sexo em sentido estrito: a sexualidade será sobretudo "uma maneira de ser no mundo físico e inter-humano" (MERLEAU-PONTY, 2011, p. 219). Assim, sem ser objeto

\footnotetext{
${ }^{12}$ Que entende o assunto como uma relação de estímulos exteriores entre prazer e dor.

${ }^{13}$ Que compreende a sexualidade como efeito de uma consciência cognitiva.
} 
expresso de uma consciência tética, é ela quem fomenta a forma geral da existência humana, e, permeando as camadas desta mesma existência, é por ela que o homem projeta seu modo de ser e seu estilo.

A sexualidade é, assim, vista como um dos modos intencionais pelos quais, espontaneamente, o sujeito toma posse do meio. Se um sujeito se caracteriza, por exemplo, por atitudes de fuga ou solidão, talvez seja esta "uma expressão generalizada de certo estado de sexualidade" (GILES, 1979, p. 259). E é por isto, portanto, que a vida sexual não pode ser somente o genital ou o instintivo, pois é, sobretudo, o poder que o sujeito psicofísico (corpo) tem de fixar-se em múltiplos ambientes e experiências. Em MerleauPonty, é a sexualidade quem, diluída na existência, não somente faz com que um homem adquira estruturas de conduta, mas que, em relação com a alteridade, erija sua história.

"Por ser essa existência a retomada e a explicação de uma situação sexual, e por ela ser desse modo, sempre tem pelo menos um duplo sentido. Há uma espécie de osmose entre a sexualidade e a existência, pois se a existência se difunde na sexualidade, reciprocamente a sexualidade se difunde na existência" (GILES, 1979, p. 259)

Prosseguindo, podemos assim dizer que a sexualidade assume um lugar privilegiado a partir de Merleau-Ponty, uma vez que, enquanto intencionalidade ambígua, não nos mostra apenas nossa abertura para alteridade e nosso estilo de ser, mas evidencia também certo principio de indeterminação onde a mesma (sexualidade) se "dilui em nossa existência" (MANZI FILHO, 2013, 128):

"quando dirijo minha mão para um objeto, sei implicitamente que meu braço se distende. Quando movo os olhos, levo em conta seu movimento sem tomar consciência expressa dele, e compreendo através dele que a desordem do campo visual é apenas aparente. Da mesma maneira a sexualidade, sem ser objeto de um ato de consciência expresso, pode motivar as formas privilegiadas da minha experiência. [...] A existência é em si indeterminada por causa da sua estrutura fundamental, já que ela é a própria operação através da qual o que não tinha sentido adquire um sentido, o que só tinha um sentido sexual adquire uma significação mais geral, o acaso se faz razão enquanto ela é a retomada de uma situação de fato. Chamaremos de transcendência esse movimento pelo qual a existência, por sua conta, retoma e transforma uma situação de fato. [...] Justamente por ser transcendência, a existência nunca ultrapassa nada definitivamente [...] ela nunca abandona a sí mesma." (MERLEAU-PONTY, 2011, pp. 233-234) 
Para Merleau-Ponty, nossa vida sexual não só expõe um modo de ser dialético num mundo físico e inter-humano, como evidencia a maneira geral pela qual o homem encarnado (ser-no-mundo) se relaciona com o as coisas. Com efeito, para o filósofo é necessário desconsiderar "o sistema nervoso, por exemplo, como 'superior' em si ao sistema sexual" (MERLAU-PONTY, 2006, p. 234), haja vista que não se estabelece entre corpo, existência e sexualidade uma relação hierárquica (tudo está pressuposto mutuamente). Sendo assim, sem ser objeto de uma consciência, a sexualidade não é nem transcendência da vida humana, nem imagem de suas representações inconscientes. Constantemente presente como uma atmosfera ambígua, da região onde habita (corpo), a sexualidade é determinante e determinada pela existência - ela "é coextensiva à vida" (Cf, GILES, 1979, p. 258).

Evitando certos pressupostos segundo os quais a sexualidade seria antes "uma camada de fatos aos quais outros domínios da existência seriam remetidos" (FERRAZ, 2006, p. 100), em Merleau-Ponty, o corpo sexuado pode muito bem ser a oportunidade de tantas observações e decisões em si mesmas verdadeiras, justas e sensatas, que se torna quase impossível, para o sujeito, enquadrar-se em qualquer determinismo: "como atmosfera ambígua, a sexualidade é coextensiva à vida. [...] o equívoco é essencial à existência humana, e tudo que vivemos ou pensamos sempre tem vários sentidos" (MERLEAU-PONTY, 2011, p. 233) Há, na Fenomenologia da Percepção, o pressuposto de que sexualidade e existência se difundem de maneira tal que se torna impossível determinar, para cada situação, "a parte de motivação sexual e a parte de outras motivações" (MERLEAU-PONTY, 2011, p. 234). Sendo a existência um pressuposto que, em sua própria natureza (realidade encarnada), é um em-si indeterminado, há na vida humana um princípio que garante à vida sexual estar "integrada ao nosso movimento no mundo" (MANZI FILHO, 2013, 130).

Para o francês, diferentemente, por exemplo, da psicanálise e de certo determinismo científico, todas as funções humanas são rigorosamente solidárias entre sí: "é impossível distinguir no ser total do homem uma organização corporal, que seria como um fato contingente, e outros predicados que lhe pertenceriam por necessidade" (GILES, 1979, pp. 259-260). O homem é uma função viva que, enquanto totalidade, é uma “ideia histórica e não uma espécie natural": somos o que somos e o que pensamos ser "sobre a base de fato que fazemos nossa" em relação ao outros. Deste modo, é impossível separar o sexual do não-sexual, uma vez que a própria existência, sendo a medida de nossas mudanças, nos 
obriga a reconhecer a indeterminação de nossas necessidades "naturais". Assim como nossos outros modos de ser no mundo ${ }^{14}$, a sexualidade não é, portanto, nem fechada em sí mesma, nem mais que ela mesma; ela é nosso ser por inteiro, sendo que "a vida sexual normal está integrada no conjunto do comportamento" de cada pessoa (MERLAU-PONTY, 2006, p. 234).

A partir de Merleau-Ponty, ninguém está inteiramente salvo, muito menos inteiramente perdido, pois, se de um lado o corpo sexuado é abertura para o mundo e estilo de nossa existência, por outro é intencionalidade e poder de significação. E se voltarmos, portanto, à Freud, veremos que grande parte dos problemas descritos pela psicanalise não remetem necessariamente à uma estrutura sexual que, de uma causalidade própria, determinaria as demais esferas da vida, mas diz respeito antes à atitude geral de ser no mundo que, por sua vez, envolverá sempre o campo afetivo e sexual. Posta a partir de bases fenomenológicas, a reinterpretação à luz do filósofo francês acerca da sexualidade não apenas devolve o ser a sua vivência de mundo, como, em primeira pessoa, dissolve a ideia de uma identidade estática e objetiva. Como uma presença inalienável, para MerleauPonty, nossa identidade é sempre implícita e misteriosa.

\section{Considerações Finais}

De acordo com a leitura que fizemos de Merleau-Ponty, a relação que mantemos com o mundo está constantemente incluída na relação do corpo consigo mesmo. Todavia, se este só faz sentido quando compreendido em relação com outras realidades sensíveis, é necessário ter em vista uma atmosfera que, para além de uma experiência estritamente subjetiva, evidencie nossa relação com o mundo sem apresentar-se independente da infraestrutura existencial humana. Tornando evidente as insuficiências das teorias clássicas, devemos compreender como as coisas se dispõem para nós pelos afetos para assim entendermos melhor como elas podem em geral existir.

Sendo necessário considerarmos um EROS ou uma LIBIDO capazes de animar um mundo original e esboçar o uso que cada sujeito fará de seu corpo, o autor põe em cheque tanto a existência de uma reflexologia condicionada, quanto a imperatividade de certos estados puros de prazer. Torna evidente o nosso modo de investimento no mundo: a

\footnotetext{
${ }^{14}$ Dentre estes, podemos citar, por exemplo, a esferas política, artística, religiosa, etc.
} 
intencionalidade original do corpo num mundo onde o sexo é "maneira de existir com ou contra os outros, de viver neles ou por eles [...], de resgatar ou de perder o passado na criação ou na repetição do presente" (CHAUI, 2002, pp. 68-69).

Pela via da sexualidade, meu corpo e o de outrem são um único fenômeno, um único todo. O contato com a alteridade é, assim, um dos modos pelos quais o ser toma posse e interage com o meio, uma vez que torna claro um saber sedimentado que vai além de uma experiência para mim sem, contudo, ser ato tético de uma consciência. Enquanto sistema aberto em direção à alteridade, o corpo como ser sexuado projeta o modo de ser do sujeito diante de outras realidades sensíveis; o que, por sua vez, nos abre para a mútua pressuposição entre existência e estrutura erótica. A sexualidade deixa, com isto, de constituir um ciclo autônomo e independente dos outros domínios da existência. Enquanto signo privilegiado, o que se observa é a mútua pressuposição entre existência e vida sexual. E é neste contexto onde a abordagem fenomenológica encontra na psicanálise freudiana um campo fértil para repensar a sexualidade.

De fato, tanto para a psicanálise quanto para a fenomenologia, o homem não é somente o resultado de processos fisiológicos ou intelectivos isolados, mas constitui um sentido histórico e cultural. Ambas as correntes reconhecem um sentido intrínseco para todo ato humano. Contudo, de uma teoria elaborada em "terceira pessoa", no que tange a psicanálise, caberia ao terapeuta não só fazer com que o paciente trouxesse à consciência o material reprimido, mas torná-lo capaz de resolver e saber objetivamente o que há por trás de seus problemas. Assim, se é a sexualidade quem faz com que o homem erija uma história, ela jamais pode ser entendida como uma realidade extrínseca e autônoma, pois está ligada a todo ser cognoscente e atuante. Trabalhando com a perspectiva merleaupontiana, tal horizonte será recíproco às demais esferas da vida, sendo impossível limitarmos a libido estritamente ao sexo.

Para o filósofo francês, a sexualidade será sobretudo um modo de ser no mundo inter-humano; a oportunidade de familiarizarmo-nos com a humanidade em seu drama mais geral, a saber: num só tempo, autônoma e dependente. Sob esta ótica, poderemos vislumbrar, então, uma ampliação de tal horizonte, agora compreendido a partir de uma relação osmótica entre existência e vida afetiva. Ligando a sexualidade à ambiguidade do corpo próprio, nossa vida afetiva representa um dos modos intransponíveis de nossos investimentos mundanos. Evidenciando certo princípio de indeterminação que não apenas difere de uma representação subjetiva, como também não diz respeito à alguma falha do 
entendimento humano, a partir de Merleau-Ponty nossa existência é, enfim, ambígua, indeterminada e misteriosa, pois tudo o que somos, o somos em relação ao outro.

\section{BIBLIOGRAFIA}

CHAUI, M. Experiência do pensamento: ensaios sobre a obra de Merleau-Ponty. São Paulo: Martins Fontes, 2002.

DUPOND, P. Vocabulário de Merleau-Ponty. São Paulo: Wmfmartinsfontes, 2010. FENICHEL, O. Teoria psicanalítica das neuroses. Rio de Janeiro: Atheneu, 1981.

O transcendental e o existente em Merleau-Ponty. São Paulo: Associação Editorial Humanitas, 2006.

FREUD, S. A interpretação dos sonhos. Rio de Janeiro: Imago, 2001

. (1905). Três ensaios sobre uma teoria da sexualidade. In: FREUD, S. Obras completas. Rio de Janeiro: Imago, 1989. 7v.

FURLAN, R. Introdução à Filosofia de Merleau-Ponty: contrapontos com Freud e Wittgenstein. 1998. Tese (Doutorado em Filosofia) - Instituto de Filosofia e Ciências Humanas, Universidade Estadual de Campinas, Campinas, 1998. Disponivel em: <http://www.bibliotecadigital.unicamp.br/document/?view=vtls000129490>. Acesso em: $11 / 09 / 2014$

GILES, T. Critica fenomenologica da psicologia experimental em merleau-ponty. Petropolis: Editora Vozes Ltda, 1979.

JORGE, M. A. C. Fundamentos da psicanálise de Freud a Lacan. Rio de janeiro: Jorge Zahar, 2008a. 1v.

JORGE, M. A. C. Fundamentos da psicanálise de Freud a Lacan. Rio de janeiro: Jorge Zahar, 2008b. 2v.

LAPLANCHE, J.; PONTALIS, J. B. Vocabulário da psicanalise. São Paulo: Martins Fontes, 1986.

MANZI FILHO, R. Quando os corpos se invadem: Merlau-Ponty às voltas com a psicanálise. 2013. Tese (Doutorado em Filosofia) - Faculdade de Filosofia, Letras e Ciências Humanas, Universidade de São Paulo, São Paulo, 2013. Disponível em: <http://www.teses.usp.br/teses/disponiveis/8/8133/tde-08112013-120854/>. Acesso em: 08/09/2014.

MERLEAU-PONTY, M. A estrutura do comportamento. São Paulo: Martins Fontes, 2006.

Fenomenologia da percepção. 4. ed. São Paulo: Martins Fontes, 2011.

Merleau-Ponty na Sorbonne: resumo de cursos filosofia e linguagem: resumo de cursos. Campinas: Papirus, 1990 a.

Psicologia e pedagogia da criança: curso da Sorbonne, 1949-1952. São Paulo: Martins Fontes, 2006.

NÁSIO, J-D. Introdução às obras de Freud, Ferenczi, Groddeck, Klein, Winnicott, Dolto, Lacan. Rio de Janeiro: Zahar, 1995.

WAELHENS, A. Uma Filosofia da Ambiguidade. In: MERLEAU-PONTY, M. A estrutura do comportamento. São Paulo: Martins Fontes, 2006. pp. I-XXV. 